\title{
Survey of HBsAg-positive pregnant women and their infants regarding measures to prevent maternal-infantile transmission
}

\author{
Yan Guo ${ }^{\dagger}$, Jianqiong Liư, Liping Meng, Hu Meina, Yukai Du*
}

\begin{abstract}
Background: Intrauterine infection is the main contributor to maternal-infantile transmission of HBV. This is a retrospective study of $158 \mathrm{HBsAg-positive} \mathrm{pregnant} \mathrm{women} \mathrm{who} \mathrm{delivered} \mathrm{children} \mathrm{from} \mathrm{Jan} \mathrm{1st,} 2004$ to Dec.31th, 2006 in Wuhan City, China. We investigated the measures taken to prevent maternal-infantile transmission of hepatitis $B$ virus and the infection status of children.

Methods: HBsAg-positive pregnant women were selected by a random sampling method when they accepted prenatal care in district-level Maternal and Child Health Hospitals. On a voluntary basis, these women completed questionnaires by face-to-face or phone interviews. The collected data were used to evaluate the immunization programs that pregnant women had received for preventing hepatitis B maternal-infantile transmission.

Results: Among the 158 women, 143(90.5\%) received Hepatitis B immune globulin during pregnancy, and 86.0\% of their children were given Hepatitis B immune globulin and Hepatitis B vaccine. The rate of cesarean section was $82.3 \%$, and $28.5 \%$ of these were aimed at preventing HBV infection. The rate of bottle feeding was $51.9 \%$, and $89.0 \%$ of bottle feeding cases were for the purpose of preventing HBV infection. There were 71 cases of participants who were HBeAg-positive. Compared with the HBsAg+ HBeAg- group (only HBsAg-positive), the $\mathrm{HBsAg}+\mathrm{HBeAg}+$ group (HBsAg-positive and HBeAg-positive) had significantly higher rates of the caesarean section and bottle feeding resulting from hepatitis $B(P<0.05)$. Five cases were HBsAg-positive by Umbilical Cord Blood detection. The intrauterine infection rate of newborns was $6.7 \%$. The chronic HBV rate of children was $4.0 \%$.

Conclusion: Most HBsAg positive pregnant women have a growing awareness of maternal-infantile transmission of Hepatitis B virus and are receiving some form of preventative treatment, like combined immunization. Caesarean and bottle feeding are very common, often primarily to prevent transmission. Relatively few intrauterine infections were identified in this sample, but many infants did not appear to seroconvert after vaccination.
\end{abstract}

\section{Background}

Hepatitis $B$ virus infection is a serious public health problem. China has a high incidence of HBV infection, with a $10 \% \mathrm{HBsAg}$ positive rate in the general population. There are more than 130 million chronic carriers of HBV in China, $30 \% \sim 50 \%$ of which can be attributed to maternal-infantile transmission[1]. Intrauterine infection is the main contributor to maternal-infantile transmission of HBV. The intrauterine infection rate of HBsAg

\footnotetext{
* Correspondence: duyukai100@yahoo.com.cn

+ Contributed equally

The Department of Maternal and Child Health, School of Public Health, Tongji Medical College, Huazhong University of Science and Technology, 430030, China
}

-positive pregnant women is $5 \% \sim 40.1 \%[2,3]$. The existing combined immunization program, whereby high-risk newborns receive Hepatitis B immune globulin (HBIG) and hepatitis $B$ vaccine, can effectively decrease motherto-child transmission of HBV during delivery and postpartum, but the immune failure rate is still high, at $20 \%$ $\sim 30 \%[4]$.

Using HBIG before childbirth[5] has been shown to be effective in preventing intrauterine HBV infection, but the efficacy of any specific program of immunization is as yet inconclusive. There are very few retrospective studies on the implementation status and outcomes of combined immunization programs since they were first put into practice. In the present study, we retrieved all 
immunization and treatment records for $\mathrm{HBsAg}$ positive pregnant women and their infants from Jan 1st, 2004 through Dec.31th, 2006 in the city of Wuhan. Combined with a designed questionnaire, we investigated the immunization program that pregnant women received to prevent maternal-infantile transmission of hepatitis B and also evaluated the status of HBV infection in the children after combined immunization.

\section{Methods}

\section{Subjects}

The HBsAg-positive pregnant women and their children were selected as study subjects from among those who had accepted prenatal care in the district-level Maternal and Child Health Hospitals of Wuhan City, between Jan 1st, 2004 to Dec.31th, 2006. Of these, 158 cases were brought into the study. Based on a hepatitis laboratory tests, they were divided into two groups: the HBsAg+ $\mathrm{HBeAg}$ - group (only HBsAg-positive) and the HBsAg + $\mathrm{HBeAg}+$ group (HBsAg-positive and HBeAg-positive). Those who accepted combined immunization and had umbilical cord blood test results and the vein test results after the full vaccination were selected for interview, and the data were used to evaluate the status of their children's HBV infection after combined immunization.

\section{IRB Approval/Informed consent}

The study protocol will be reviewed and approved by the Institutional Review Board of Tongji Medical College, Huazhong University of Science \& Technology, 2007(02). Data files and completed questionnaires are kept under lock and key to ensure confidentiality of respondents.

Informed consent was obtained from the HBsAg-positive pregnant women and their children.

\section{Data collection}

Adopting the retrospective method, correlative information was retrieved from maternal prenatal health care manuals of the HBsAg-positive pregnant women. This included factors such as check-ups during early pregnancy, treatments to prevent maternal-infantile transmission of HBV, method of delivery and feeding etc. Trained investigators conducted face-to-face or telephone interviews with the women based on a voluntary and confidential principle using uniform questionnaires. The content of the questionnaires included the profiles and test results of HBV, while also determining the immunization and HBIG treatment before and after delivery, delivery situation and feeding patterns etc. Questionnaires were checked after being collected, and the entry-related information was analyzed by being contrasted with recorded information from manuals.

\section{Diagnostic Criteria}

Diagnostic criteria for pregnant women infected with HBV were in accordance with the diagnosis criteria of the National Conference on Viral Hepatitis in October 2000 in Xi'an, China [6]. The diagnostic criterion for intrauterine infection of newborns was HBV-DNA $>1.0 \mathrm{e}$ +003 in umbilical cord blood test results (PCR) during delivery. The diagnostic criterion for chronic HBV infection of children was HBsAg-positive serum for six months or more[7,8].

Combined Immunization consisted of injection of HBsAg positive pregnant women with HBIG during pregnancy, and their children were later given HBIG and Hepatitis B vaccine.

\section{Statistical analysis}

EpiData 3.02 was used to establish the database. The data were converted into an SAS database after being checked by being input twice, and then analyzed statistically with SAS version 8.1 software. Descriptive analysis (the calculation of average or frequency, proportion or rate) was conducted. Single-factor analysis: $\left(\chi^{2}\right.$ test or $\mathrm{t}$ test) was used to compare the difference of qualitative data or quantitative data, respectively.

\section{Results}

\section{HBsAg positive description}

A total of 158 cases were $\mathrm{HBsAg}$ positive in the random sample (2026 pregnant women were enrolled), corresponding to a HBV positive rate of 7.8 percent. Among the 158 cases investigated, 127 cases $(80.4 \%)$ had only $\mathrm{HBsAg}$-positive (HBsAg+ HBeAg-group) and 31 cases (19.6\%) had the combined HBsAg and HBeAg-positive (double - positive group). The statistical analysis showed no significant differences in age, occupation, education level, income, or other general socio-economic status between the HBsAg+ HBeAg- group (only HBsAg-positive) and HBsAg + HBeAg+ group (HBsAg-positive and HBeAg-positive), $(P>0.05)$, indicating that the two groups were comparable.

\section{Immunization program}

Among the 158 cases of HBsAg positive pregnant women, 143 (90.5\%) cases received HBIG, and 86.0\% of their children were given HBIG and Hepatitis B vaccine. Among the 158 women, $82.3 \%$ accepted cesarean section, of which $28.5 \%$ were aimed at preventing HBV infection. The rate of bottle feeding was $51.9 \%$, and $89.0 \%$ of bottle feeding cases were for the purpose of preventing HBV infection. In contrast, in HBsAg negative pregnant women $(1868 / 2026)$, the cesarean section ratio was $73.47 \%$, and bottle feeding ratio was $41.80 \%$. Both of these were significantly lower than the 
rates of HBsAg positive pregnant women $\left(\chi^{2}=5.9250\right.$, $P=0.0149 ; \chi^{2}=6.0647, P=0.0138$ ).

There was no significant difference in the percentage of women who received HBIG during pregnancy between the HBsAg+ HBeAg- group and the HBsAg + HBeAg+ group (Table 1). However, the caesarean section rate of the HBsAg + HBeAg+ group was significantly higher than the HBsAg+ HBeAg- group $(P<$ 0.05). More double-positive than single-positive women opted for bottle feeding $(P<0.05)$.

\section{HBV infection of children}

To determine the HBV status of children after combined immunization, 75 cases were chosen from the investigated HBsAg-positive pregnant women. Umbilical cord blood and vein blood from these women and their children were tested for HBV serological markers by lab tests after full vaccination. Of these 75 cases, 54 were from $\mathrm{HBsAg}+\mathrm{HBeAg}$ - group and 21 were from $\mathrm{HBsAg}$

Table 1 Comparison of intervention measures between the $\mathrm{HBsAg}+\mathrm{HBeAg}$ - group and $\mathrm{HBsAg}+\mathrm{HBeAg}+$ group

\begin{tabular}{|c|c|c|c|c|}
\hline & $\begin{array}{c}\text { Single- } \\
\text { positive } \\
\text { group (127) }\end{array}$ & $\begin{array}{l}\text { Double- } \\
\text { positive } \\
\text { group (31) }\end{array}$ & & \\
\hline $\begin{array}{l}\text { Interruption } \\
\text { measures }\end{array}$ & n (\%) & n (\%) & $\chi^{2}$ & $P$ \\
\hline $\begin{array}{l}\text { Pregnancy HBIG } \\
\text { Injected }\end{array}$ & & & 0.9726 & 0.3240 \\
\hline yes & $113(89.0)$ & $30(96.8)$ & & \\
\hline no & $14(11.0)$ & $1(3.2)$ & & \\
\hline $\begin{array}{l}\text { Infant } \\
\text { immunization }\end{array}$ & & & 1.2889 & 0.2563 \\
\hline $\begin{array}{l}\text { Hepatitis B } \\
\text { vaccine }\end{array}$ & $23(18.1)$ & $3(9.7)$ & & \\
\hline $\begin{array}{c}\text { Hepatitis B } \\
\text { vaccine \& HBIG }\end{array}$ & $104(81.9)$ & $28(90.3)$ & & \\
\hline $\begin{array}{l}\text { Combined } \\
\text { immunization }\end{array}$ & & & 3.4802 & 0.0621 \\
\hline yes & $95(74.8)$ & $28(90.3)$ & & \\
\hline no & $32(25.2)$ & $3(9.7)$ & & \\
\hline Cesarean section & & & 1.7115 & 0.1908 \\
\hline yes & 102(80.3) & $28(90.3)$ & & \\
\hline no & 25(19.7) & $3(9.7)$ & & \\
\hline $\begin{array}{l}\text { Cesarean section } \\
\text { due to HBV } \\
\text { infection }\end{array}$ & & & 18.2321 & $<0.0001$ \\
\hline yes & 20(19.6) & $17(60.7)$ & & \\
\hline no & $82(80.4)$ & $11(39.3)$ & & \\
\hline Bottle feeding & & & 26.7994 & $<0.0001$ \\
\hline yes & $53(41.7)$ & 29(93.6) & & \\
\hline no & $74(58.3)$ & $2(5.4)$ & & \\
\hline $\begin{array}{l}\text { Bottle feeding due } \\
\text { to HBV infection }\end{array}$ & & & 3.9302 & 0.0474 \\
\hline yes & $44(83.0)$ & $29(100.0)$ & & \\
\hline no & $9(17.0)$ & $0(0.0)$ & & \\
\hline
\end{tabular}

+ $\mathrm{HBeAg}+$ group. In total, 5 cases were $\mathrm{HBsAg}$-positive as determined by umbilical cord blood test ( 1 from $\mathrm{HBsAg}+\mathrm{HBeAg}$ - group, and 4 from $\mathrm{HBsAg}+\mathrm{HBeAg}+$ group). The overall intrauterine infection rate was $6.7 \%$. A total of 20 out of 75 cases were HBsAb positive, for a positive rate of $26.7 \%$.

Intrauterine infection rate of the $\mathrm{HBsAg}+\mathrm{HBeAg}+$ group (19.1\%) was significantly higher than that of the HBsAg+ HBeAg- group (1.9\%), emendation $\chi^{2}=4.6875$, $P=0.0304$ (Table 2). In all, 3 cases that were HBsAgpositive at birth turned negative after the full vaccination. Their mothers all were $\mathrm{HBsAg}$ and $\mathrm{HBeAg}$ positive. The rate of chronic HBV infection in children was $4.0 \%$.

\section{Discussion}

The HBV carrying rate of pregnant women in Wuhan has reportedly decreased in recent years[9]. The present survey showed that from 2004 to 2006, the HBV carrying rate was $7.8 \%$ for this region. This rate was not only higher than that of developed countries, such as European countries and the United States[10], but it was also higher than that of many developing countries $[11,12]$. This might be attributed, at least in part, to the increase in HBV screening.

Maternal-infantile transmission is an important transmission route for HBV; thus, strategies aimed at interrupting this pathway would largely reduce the number of new infections and would mitigate the suffering imposed by the disease on the families, society, and individuals. In the current study, maternal-infantile transmission was low with combined immunization, in which the pregnant women receive HBIG injection during pregnancy and their newborns get HBIG and Hepatitis

Table 2 Comparison of the HBV infection of children between the $\mathrm{HBsAg}+\mathrm{HBeAg}-$ group and $\mathrm{HBsAg}+\mathrm{HBeAg}+$ group

\begin{tabular}{lcccc}
\hline & $\begin{array}{c}\text { Single-positive } \\
\text { group (127) }\end{array}$ & $\begin{array}{c}\text { Double- } \\
\text { positive group } \\
\text { (31) }\end{array}$ & & \\
\hline Infants Outcome & $\mathbf{n ~ ( \% )}$ & $\mathbf{n}$ (\%) & $\boldsymbol{\chi}^{\mathbf{2}}$ & $\mathbf{P}$ \\
\hline $\begin{array}{l}\text { Intrauterine } \\
\text { infection }\end{array}$ & & & 4.6875 & 0.0304 \\
$\quad$ yes & $1(1.9)$ & $4(19.1)$ & & \\
no & $53(98.1)$ & $17(80.9)$ & & \\
HBsAb positive & & & 0.0541 & 0.8161 \\
$\quad$ yes & $14(25.9)$ & $6(28.6)$ & & \\
no & $40(74.1)$ & $15(71.4)$ & & \\
HBV serological & & & 3.5465 & 0.0597 \\
markers full- & & & & \\
negative & & & & \\
$\quad$ yes & $39(62.2)$ & $11(52.3)$ & & \\
no & $13(37.8)$ & $10(47.7)$ & & \\
\hline
\end{tabular}

(HBV serological markers include the five items in table 1.) 
$B$ vaccine after birth. This is in agreement with another study, which suggested that up to $95 \%$ of maternalinfantile transmission can be blocked by using motherand-baby combined immunization [13]. In our survey, $86 \%$ of the HBsAg-positive pregnant women received HBIG before delivery, and their children were given HBIG and Hepatitis B vaccine. The percentage of chronic HBV infection in infants with the combined immunization program was $4.0 \%$, which was much lower than those without vaccination $(80 \%$ 95\%)[14], and also lower than those whose mothers had not received HBIG $(10 \% \sim 15 \%)[15]$. It is possible that a HBsAg-positive reaction could change to negative in children with combined immunization[16]. Despite this, most children still lack HBsAb and are extremely susceptible to HBV infection. The reason could be two possibilities. One was insufficient or inefficient vaccination, the other was the times of producing antibodies differing in diverse people, which leads to different outcomes after the full-course vaccination. If children have no $\mathrm{HBsAb}$ after full vaccination, they will be advised to be revaccinated for HBV.

Mothers with positive $\mathrm{HBeAg}$ are at high risk for intrauterine transmission. Therefore, women who are positive for HBeAg should be taken into special consideration to prevent maternal-infantile transmission of HBV. When a mother is HBV positive, a caesarean section may be done to protect the baby from direct contact with her blood and other bodily fluids. This survey has shown that more than $80 \%$ of pregnant women with positive HBsAg opted for cesarean section. Some studies suggest that cesarean section could reduce the likelihood of HBV infections in the infants $[18,19]$, whereas other researchers found no difference in maternal-infantile transmission of HBV between women with cesarean section and natural birth. This is an important consideration, as cesarean section will increase medical costs, prolong length of stay in hospital, and can add additional complications due to operation syndrome.

More than half of the investigated mothers also opted for bottle feeding. As seen with cesarean section, double- positive pregnant women were more worried about the risk of transmission of HBV via breast milk, which is still controversial $[20,21]$.

Although recent studies have shown the effectiveness of a combined immunization program in prevention of vertical HBV transmission and the benefits of active and passive immunization of infants have been recognized, the effects of injecting HBIG before delivery are still controversial $[22,23]$. At present, almost all HBsAg-positive pregnant women and even $\mathrm{HBsAg}$-positive, HBeAbpositive and $\mathrm{HBCAb}$-positive women, are not recommended for treatment with HBIG during pregnancy at most hospitals in Wuhan City. Thus, the increase in intrauterine infection and chronic infection is still a concern. According to the principles of evidence-based medicine, a well-designed and forward-looking study is needed, with large samples in multi-center organizations. We can then make a comprehensive assessment of the effects of giving HBIG to pregnant women for prevention of maternal-infantile transmission of HBV.

\section{Conclusion}

Most HBV positive pregnant women have a growing awareness of maternal-infantile transmission of Hepatitis $B$ virus and are receiving some form of preventative treatment. For example, their children are given HBIG and Hepatitis B vaccine and/or HBsAg positive pregnant women are injected with 3-5 doses of HBIG during pregnancy. Caesarean section and bottle feeding are very common, often performed primarily to prevent HBV transmission. Relatively few intrauterine infections were identified in this sample, but many infants did not appear to seroconvert after vaccination.

\section{Acknowledgements}

We thank all the pregnant women, their children, and health care workers who participated in this study. We also thank Prof. Jinwei Yuan for for advice and review of the study. This study was supported by Grant 04513052 from the National Natural Science Foundation of China to YD.

\section{Authors' contributions}

YG carried out the retrospective studies, participated in the design of the study and performed the statistical analysis and drafted the manuscript. $J$, $\mathrm{LM}$ and $\mathrm{MH}$ carried out the field investigation and participated in the statistical analysis. YD conceived of the study, and participated in its design and coordination and helped to draft the manuscript. All authors read and approved the final manuscript.

\section{Competing interests}

The authors declare that they have no competing interests.

Received: 15 April 2009

Accepted: 15 February 2010 Published: 15 February 2010

\section{References}

1. Cacciola I, Cerenzia G, Pollicino T, et al: Genomic heterogeneity of hepatitis $B$ virus(HBV) and outcome of perinatal HBV infection. $J$ Hepatol 2002, 36(3):426-432.

2. Lok-kit: Obstetrics and Gynecology. The people of Health Press, Sixth 2005.

3. Zhang SL, Yue YF, Bai GQ, et al: Mechanism of intrauterine infection of hepatitis B virus. World J Gastroenterol 2004, 10(3):437-438.

4. Huang K, Lin S: Nationwide vaccination:a success story in Taiwan. Vaccine 2000, 18(Suppll):535-538.

5. Yan Y-P, Li R, Xu D-Z, et al: Meta-analysis of intrauterine infection rate of HBV in different periods of pregnancy. Journal of the Fourth Military Medical University 2002, 23(9):853-855.

6. Chinese National Viral Hepatitis Prevention Conference: Viral Hepatitis Control Programme. Chinese Journal of Infectious Diseases 2001, 19(1):56-62.

7. Liu Y-P, Shao Z-J, Xu D-Z, et al: Study on the blocking effect of injecting $\mathrm{HBsAg}$ positive mothers during pregnancy and their infants at birth with HB immunoglobulin on mother-to-infant transmission of HBV. Chinese Journal of Disease Control \& Prevention 2004, 8(2):109-110.

8. Wang J-S: A Long-term Follow-up of Hepatitis B Vaccine Inoculated and $\mathrm{HB}$ Immunoglobulin Combinely Immunized Infants Born to $\mathrm{HBsAg}$ Positive Mothers. Chinese Journal of Vaccines and Immunization 2001, 7(2):96-99. 
9. Yu B, Zhou D-J, Xia J-N, et al: Epidemiological Survey on Vaccination Rate of Neonatal Hepatitis B Vaccine and Carrier Rate of Maternal Hepatitis B Virus in 2003 in Wuhan City. Disease Surveillance 2005, 20(11):576-578.

10. Denis F, Ranger-Rogez $S$, Alain $S$, et al: Screening of pregnant women for hepatitis B markers in a French Provincial University Hospital (Limoges) during 15 years. Eur J Epidemiol 2004, 19(10):973-978.

11. Akani Cl, Ojule AC, Opurum HC, et al: Sero-prevalence of Hepatitis B Surface Antigen ( $\mathrm{HBsAg}$ ) in pregnant women in Pport Harcourt, Nigeria. Niger Postgrad Med J 2005, 12(4):266-270.

12. Bertolini DA, Pinho JR, Saraceni CP, et al: Prevalence of serological markers of hepatitis B virus in pregnant women from Parana State, Brazil. Braz J Med Biol Res 2006, 39(8):1083-1090.

13. Dong Z-Q, Zhang $X-Z$, Gu X-H, et al: A randomized controlled trial on interruption of HBV transmission in uterus. Chinese Journal of Pediatrics 2002, 40(8):478-480,

14. Plitt SS, Somily AM, Singh AE: Outcomes from a Canadian public health prenatal screening program for hepatitis B:1997-2004. Can J Public Health 2007, 13(9):518-526.

15. Sangfelt $P$, Von $S M$, Uhnoo I, et al: Serum ALT levels as a surrogate marker for serum HBV DNA levels in HBeAg-negative pregnant women. Scand J Infect Dis 2004, 36(3):182-185.

16. Wang J-S, Zhu Q-R: Long term follow-up results of Hapatitis B vaccine single use and combination use with HBIG in blocking HBV mother infant transmission. Chinese Journal of Practical Pediatrics 2000, 9(15):558-560

17. Wang $Z$, Zhang $H$, et al: Quantitative analysis of HBV DNA level and $\mathrm{HBeAg}$ positive mothers and their babies: $\mathrm{HBsAg}$ passage through the placenta and rate of decay in babies. J Med Virol 2003, 71(3):360-6.

18. Lin $\mathrm{HH}$, Kao JH, Hsu HY, et al: Least microtransfusion from mother to fetus in elective cesarean delivery[J]. Obstet Gynecol 1996, 87(2):244-248.

19. Lin $\mathrm{HH}$, Kao JH, Hsu HY, et al: Least microtransfusion from mother to fetus in elective cesarean delivery. Obstet Gynecol 1996, 87(2):244-248.

20. Wang JS, Zhu QR, Wang XH: Breastfeeding does not pose any additional risk of immunoprophylaxis failure on infants of HBV carrier mothers. Int $J$ Clin Pract 2003, 57(2):100-102.

21. Zheng D-Y, Mo K-L, He H-Y, et al: Investigation ofreliability on Breast feeding to infants of HBV-carrying pregnants after the Joint Immune. Progress in Obstetrics and Gynecology 2006, 15(2):125-127.

22. Li XM, Yang YB, Hou HY, et al: Interruption of HBV intrauterine transmission: a clinical study. World J Gastroenteorl 2003, 9(7):1501-1503.

23. Pan J-Y, Zhong W-P, Yan S-L, et al: Study on anti-HBV immunoglobulin in preventing intrauterine infection of HBV. Journal of Clinical and Experimental Medicine 2006, 5(I):12-13.

\section{Pre-publication history}

The pre-publication history for this paper can be accessed here:http://www. biomedcentral.com/1471-2334/10/26/prepub

doi:10.1186/1471-2334-10-26

Cite this article as: Guo et al: Survey of HBsAg-positive pregnant women and their infants regarding measures to prevent maternalinfantile transmission. BMC Infectious Diseases 2010 10:26.

\section{Submit your next manuscript to BioMed Central and take full advantage of:}

- Convenient online submission

- Thorough peer review

- No space constraints or color figure charges

- Immediate publication on acceptance

- Inclusion in PubMed, CAS, Scopus and Google Scholar

- Research which is freely available for redistribution

Submit your manuscript at www.biomedcentral.com/submit
Biomed Central 